\title{
Development of the gastrointestinal tract
}

\section{By Susan J. Henning, Department of Biology, University of Houston, Houston, TX 77004, USA}

My aim in this review is to use the rat as a model system for a discussion of the functional development of the gastrointestinal tract. I should make it clear at the outset that since the rat is an altricial species, many of the enzymic changes that occur postnatally in the rat occur prenatally in other mammals, including humans (Grand et al. 1976; Lebenthal et al. 1983). Nevertheless, 1 believe that these studies in the rat have posed some questions of broader importance and have pointed to some potential answers. Thus, the review is structured so as to emphasize the general lessons which have potential application in many species and in many organ systems. Because of space limitations, the review does not attempt to be comprehensive.

To set the stage, it is important to realize that the process of spontaneous weaning in the rat is a precisely timed phenomenon which normally begins at $17 \mathrm{~d}$ of age and is complete by day 26 (Henning et al. 1979). Weaning constitutes a significant change in dietary composition which, in turn, necessitates changes in digestive function. The entire gastrointestinal tract of the rat is functionally immature at birth and during the first two postnatal weeks. There are extensive changes in digestive capacity during the third postnatal week, and the adult modes of digestion are fully operative by the end of the fourth week. These developmental changes in gastrointestinal function have been reviewed elsewhere in detail (Henning, 1981; Klein \& McKenzie, 1983) and only those in the small intestine will be summarized here.

In the small intestine of the rat, we find that the neonate has hydrolytic activities which are specific for, and largely restricted to, the components of maternal milk. This is demonstrated very nicely by a consideration of carbohydrate digestion. Milk is relatively low in total carbohydrates, and the carbohydrates present are those not generally found in adult diets. The major carbohydrate in the milk of most placental mammals is lactose (Jenness et al. 1964), and high activities of its disaccharidase, lactase (EC 3.2.1.23), are found in the intestinal mucosa of the sucking animals (Deren, 1968; Kretchmer, 1971). In the rat, lactase is detectable on day 18 of gestation, has maximal activity during the first week after birth, and then begins to decline, reaching adult values by the end of the fourth week (Doell \& Kretchmer, 1962). Many other species, including the human, have lower lactase activity in the adult than in the newborn (Deren, 1968) and accordingly show an inability to utilize ingested lactose in the postweaning period (Kretchmer, 1971).

Intestinal hydrolases that are involved in digestion of carbohydrate components of solid food are absent or low at birth, then appear or increase in activity, or both. Maltase (EC 3.2.1.20) has low activity during the first two postnatal weeks then 
undergoes a five- to tenfold increase during the next 2 weeks (Rubino et al. 1964; Reddy \& Wostmann, 1966). For sucrase, ( $E C$ 3.2.1.48), isomaltase (EC 3.2.1.10), and $\alpha, \alpha$-trehalase ( $E C$ 3.2.1.28), the transition is even more sudden. These enyzmes cannot be detected in the intestine during the first and second postnatal weeks but their activities appear on approximately day 16 and rise rapidly, reaching adult levels by the end of the fourth week (Doell \& Kretchmer, r 964; Rubino et al. 1964; Reddy \& Wostmann, 1966). The activity changes of the disaccharidases are paralleled by quantitative changes in the amounts of enzyme protein (Henning, 198I).

\section{Regulation of enzymic changes in the small intestine}

Role of diet. The possibility of dietary influence over the regulation of intestinal development is an obvious one considering the temporal correlation between the major enzymic changes in the intestine and the onset of weaning. It is clear, however, that this dietary change cannot be considered to be the primary cause of the various enzymic changes that occur in the intestine during the third postnatal week. We have shown that when weaning is prevented, the appearance of sucrase activity in the jejunum is not delayed (Henning \& Sims, 1979). Similarly, prolonged sucking delays, but does not prevent, the usual decline of lactase activity (Lebenthal et al. 1973). Conversely, oral administration of sucrose to 12 -d-old rats has no effect on the developmental pattern for sucrase (Lebenthal et al. 1972). If sucrose is administered by gastrostomy to sucking rats, precocious increase of sucrase is observed; however, since this does not occur if the animals have been previously adrenalectomized, it is probably a stress response rather than a dietary response (Lebenthal et al. 1972). The same comment applies to the precocious appearance of sucrase, maltase, isomaltase and alkaline phosphatase (EC 3.1.3.1) following early weaning (Goldstein et al. 1971; Raul et al. 1978). These conclusions are supported by the observations that sucrase develops normally in by-passed intestinal segments (Tsuboi et al. 198I) and that when intestinal explants from 6-d-old rats are cultured in the presence of various sugars there is no stimulatory effect on sucrase or maltase activity (Raul et al. 1981).

Role of glucocorticoid hormones. The glucocorticoids are attractive candidates for the regulation of intestinal development because circulating concentrations of corticosterone (the principal glucocorticoid in the rat) increase at the beginning of the third postnatal week (Henning, 1978a,b). Administration of glucocorticoids to sucking rats during the first two postnatal weeks causes precocious increases in the activities of sucrase, maltase, trehalase, aminopeptidase (EC 3.4.I I.I I) and alkaline phosphatase, as well as precocious decreases of lactase and various lysosomal hydrolases (Henning, r 98I ; Klein \& McKenzie, 1983). Correspondingly, addition of glucocorticoids to intestinal explants from rats aged $4^{-1} 3 \mathrm{~d}$ elicits a precocious appearance of sucrase and a stimulation of maltase activity (Doell \& Kretchmer, 1964; Kedinger et al. 1980; Simon et al. 1982).

Since the intestinal epithelium is in a state of continuous turnover, the mechanism by which glucocorticoids influence enzymic change is a matter of 
considerable interest. For any agent acting on the small intestine there are two possible mechanisms by which enzymic changes could occur: by alteration of the enzyme levels in the differentiated cells that are present on the villi, or by replacement of one population of villus cells by another which has altered enzymology. Using sucrase as a marker, we (Henning et al. 1975) and others (Doell et al. 1965; Herbst \& Koldovsky, 1972; Hauri et al. 1980) have shown that it is the latter method with accounts for the precocious maturation seen after glucocorticoid administration. This has also been found to be true from the changes that normally occur in untreated animals during the third postnatal week (Williams \& Beck, 1969; Hauri et al. 1980). Thus, the maturation of intestinal enzymes is achieved by changes in the cellularity of the epithelium rather than by molecular changes in the differentiated cells of the villus.

Despite the dramatic effects of glucocorticoids on the small intestine of the sucking rats, manipulations of glucocorticoid status are without effect in the adult (Deren et al. 1967). In order to determine exactly when the intestine loses its responsiveness to glucocorticoids, we performed a series of experiments in which animals were adrenalectomized at various ages. Examination of sucrase, acid $\beta$-D-galactosidase ( $E C$ 3.2.1.22) and maltase in these animals as compared with sham-operated controls indicated that there was an abrupt loss of responsiveness to adrenalectomy at $17-18 \mathrm{~d}$ of age (Henning \& Sims, 1979; Henning \& Leeper, 1982). The converse experiment, namely the administration of glucocorticoids at various ages, showed that these enzymes, as well as lactase, did not respond to glucocorticoid elevation beyond 16-17 d (Henning \& Sims, 1979; Henning \& Leeper, 1982). What is surprising is that the age of loss of responsiveness occurs right at the beginning of the period of developmental changes, indicating that by this time the glucocorticoids have exerted their molecular action and the remainder of the developmental rise or fall of the enzyme is already programmed. Given that the endogenous increase of corticosterone beings on approximately day 14 (Henning, 1978a,b), these studies indicate that during normal ontogeny, glucocorticoids influence the intestine during a rather narrow 'window' of approximately $4 \mathrm{~d}$.

As detailed previously, the involvement of glucocorticoids in intestinal development has been extensively studied. However, the question of whether intestinal maturation is absolutely dependent on glucocorticoids has not been adequately addressed in the literature. Several studies have shown that enzymic development is delayed but not abolished in adrenalectomized rat pups (Moog, 1953; Koldovsky et al. 1965, 1975). The problem with these studies was that none of them included either mineralocorticoid replacement or measurement of serum corticosterone following the adrenalectomy. We have recently found that without mineralocorticoid administration following neonatal adrenalectomy, the only pups which survive long enough to study have substantial amounts of corticosterone in the serum. Even with mineralocorticoid replacement, it is essential to measure serum corticosterone in all adrenalectomized pups so as to eliminate those with detectable levels of corticosterone (Martin \& Henning, 1982). A recent study 
incorporating these precautions showed that although adrenalectomy markedly suppressed the rate of the sucrase rise, the time of appearance of the enzyme (day 17) was not delayed, and by day 26 the activity of the enzyme in the pups having no detectable serum corticosterone was the same as that in the sham-operated controls (Martin \& Henning, 1984). In the same study, the rate of maturation of maltase, lactase and acid $\beta$-D-galactosidase was reduced but not abolished by adrenalectomy. These results have led us to conclude that developmental changes in intestinal enzymes are not absolutely dependent on corticosterone. It seems that the timing for the initiation of enzyme development is intrinsically programmed in the intestinal tissue and that the developmental surge of serum corticosterone at the beginning of the third postnatal week controls only the rate of expression of the intestinal programme. Such a mechanism is consistent with the observation that sucrase, maltase, lactase and acid $\beta$-D-galactosidase develop normally in fetal intestinal tissue which is transplanted into the stable hormonal environment of an adult host (Kendall et al. 1977; Montgomery et al. 1981).

In view of these conclusions, we believe that the significance of glucocorticoids in intestinal development is that they provide a mechanism for precocious maturation if pups are subjected to precocious loss of their dam, i.e. that the stress of forced weaning would cause a sufficient elevation of plasma corticosterone to induce precocious maturation of intestinal enzymes. This suggestion is consistent with the finding that jejunal sucrase activity is elevated following early weaning, but only if the adrenal glands are present (Boyle \& Koldovsky, 1980). Precocious decreases of lactase activity and increases of maltase activity have also been reported in early-weaned rats (Lee \& Lebenthal, 1983; Yeh, 1983). Moreover, serum corticosterone is elevated by more than threefold as a result of early weaning (Lee \& Lebenthal, 1983).

Role of thyroxine. Thyroxine $\left(\mathrm{T}_{4}\right)$ has received considerable attention as a candidate for regulation of intestinal development in the rat because its circulating concentration rises significantly during the second postnatal week (Henning, r98I). Administration of $T_{4}$ or triiodothyronine has been shown to cause precocious decline of jejunal lactase activity (Paul \& Flatz, 1983) and ileal lysosomal hydrolases (Koldovsky et al. 1974), and precocious increases of jejunal sucrase and maltase (Jumawan \& Koldovsky, 1978). Conversely, hypothyroidism delays but does not prevent the usual decline of lactase and lysosomal hydrolases and the usual increases of sucrase and maltase activities (Yeh \& Moog, 1974, 1977; Koldovsky et al. 1975; Henning, 1978a,b). The significance of findings such as these must be questioned in view of the fact that administration of $T_{4}$ causes a precocious increase in plasma corticosterone and that hypothyroidism virtually abolishes the developmental rise of corticosterone (Malinowska et al. 1974; Yeh \& Moog, 1977; D'Agostino \& Henning, 1982). Although $T_{4}$ may play a direct role in the development of some intestinal enzymes (Henning, 1985), at least for sucrase and maltase development, the effects of thyroid manipulations seem to be secondary to the accompanying changes of serum corticosterone. Specifically, the suppressive effect of hypothyroidism on the developmental rises of sucrase and 
maltase can be reversed just as effectively by glucocorticoid administration as by $\mathrm{T}_{4}$ treatment (Yeh \& Moog, 1977; Martin \& Henning, 1982). Conversely, when $\mathrm{T}_{4}$ is administered during the first two postnatal weeks there is no stimulation of sucrase and maltase unless serum corticosterone is also allowed to increase (Martin $\&$ Henning, 1982). The conclusion that $\mathrm{T}_{4}$ plays no role in the normal development of jejunal sucrase and maltase is supported by the finding that $T_{4}$ (in contrast to glucocorticoid) is unable to elicit increases in the activity of these enzymes in jejunal explants from sucking rats (Simon et al. 1982).

\section{Conclusions}

These studies on the regulation of intestinal development in the rat have posed several questions of relevance to other species and to other organ systems. The first question is whether ontogenic changes are due to changing cellularity of the tissue as opposed to purely molecular changes within a stable population of cells. The second question is whether a tissue may be hormone-sensitive only during a very narrow developmental 'window'. This question is particularly relevant to humans, where the paucity of systematic information could lead to a negative conclusion based on studies at a single age. The third general question is whether effects of hormone manipulations are direct, as in the case of the effect of glucocorticoids on sucrase activity, or are secondary to other effects in the animal, as in the case of the effect of thyroxine on this enzyme. The fourth general question is the efficacy of endocrine ablations such as adrenalectomy. Our studies with sucrase have shown that in order to make valid conclusions, it is critical to check the serum concentrations of the relevant hormone. The fifth general question is that whereas we are accustomed to considering the possibility that certain factors may be necessary but not sufficient as cues for development, should we also, from the glucocorticoid story, consider the converse, i.e. that a hormone or other factor may be a sufficient, but not a necessary, cue?

Some of the work reported in this review was supported by grants nos. HD 14093 and HD 14094 from the National Institutes of Health.

\section{REFERENCES}

Boyle, J. T. \& Koldovsky, O. (1980). Fournal of Nutrition $110,169-177$.

D'Agostino, J. B. \& Henning, S. J. (1982). American fournal of Physiology 242, E33-E 39.

Deren, J. J. (1968). In Handbook of Physiology, Section 6, Alimentary Canal, vol. 3, pp. 1099-1123 [C. F. Code, editor]. Washington, DC: American Physiological Society.

Deren, J. J., Broitman, S. A. \& Zamcheck, N. (1967). Fournal of Clinical Investigation 46, 186-195.

Doell, R. G. \& Kretchmer, N. (1962). Biochimica et Biophysica Acta 62, 353-362.

Doell, R. G. \& Kretchmer, N. (1964). Science 143, 42-44.

Doell, R. G., Rosen, G. \& Kretchmer, N. (1965). Proceedings of the National Academy of Sciences (USA) $54,1268-1273$.

Goldstein, R., Klëin, T., Freier, S. \& Menczel, J. (1971). American foumal of Clinical Nutrition $24,1224-1231$.

Grand, R. J., Watkins, J. B. \& Torti, F. M. (1976). Gastroenterology 70, 790-8 ro. 
Hauri, H.-P., Quaroni, A. \& Isselbacher, K. J. (1980). Proceedings of the National Academy of Sciences (USA) 77, 6629-6633.

Henning, S. J. (1978a). Endocrinology 102, 9-15.

Henning, S. J. (1978b). American fournal of Physiology 235, E451-E456.

Henning, S. J. (1981). American fournal of Physiology 241, G199-G214.

Henning, S. J. (1985). Annual Review of Physiology 47, 231-245.

Henning, S. J., Chang, S.-S. P. \& Gisel, E. G. (I979). American fournal of Physiology 237, RI 87-RI9I.

Henning, S. J., Helman, T. A. \& Kretchmer, N. (1975). Biology of the Neonate 26, 249-262.

Henning, S. J. \& Leeper L. L. (1982). American Yournal of Physiology 242, G89-G94.

Henning, S. J. \& Sims, J. M. (1979). Endocrinology 104, I $158-1163$.

Herbst, J. J. \& Koldovsky, O. (1972). Biochemical fournal 126, 471-476.

Jenness, R., Regehr, E. A. \& Sloan, R. E. (1964). Comparative Biochemistry and Physiology r3, $339-352$.

Jumawan, J. \& Koldovsky, O. (1978). Enzyme 23, 206-209.

Kedinger, M., Simon, P. M., Raul, F., Grenier, J. F. \& Haffen, K. (1980). Developmental Biology $74,9-21$.

Kendall, K., Jumawan, J., Koldovsky, O. \& Krulich, L. (1977). Foumal of Endocrinology 74, $145^{-1} 4^{6}$.

Klein, R. \& McKenzie, J. C. (1983). Fournal of Pediatric Gastroenterology and Nutrition 2, $204-228$.

Koldovsky, O., Jirsova, V. \& Heringova, A. (1965). Nature 206, 300-30r.

Koldovsky, O., Jumawan, J. \& Palmieri, M. (1974). Proceedings of the Society for Experimental Biology and Medicine $146,66 \mathrm{I}-664$.

Koldovsky, O., Jumawan, J. \& Palmieri, M. (1975). Fournal of Endocrinology 66, $31-36$.

Kretchmer, N. (1971). Gastroenterology 6r, 805-813.

Lebenthal, E., Lee, P. C. \& Heitlinger, L. A. (1983). Fournal of Pediatrics 102, $1-9$.

Lebenthal, E., Sunshine, P. \& Kretchmer, N. (1972). Fournal of Clinical Investigation 51, 1244-1250.

Lebenthal, E., Sunshine, P. \& Kretchmer, N. (1973). Gastroenterology 64, 1136-1 141 .

Lee, P. C. \& Lebenthal, E. (1983). Pediatric Research 17, 645-650.

Malinowska, K. W., Chan, W. S., Nathanielsz, P. W. \& Hardy, R. N. (1974). Experientio 30, 61.

Martin, G. R. \& Henning, S. J. (1982). Endocrinology 11 I, 912-918.

Martin, G. R. \& Henning, S. J. (1984). American fournal of Physiology 246, G695-G699.

Montgomery, R. K., Sybicki, M. A. \& Grand, R. J. (1981). Developmental Biology 87, 76-84.

Moog, F. (1953). Fournal of Experimental Zoology 124, 329-346.

Paul, T. \& Flatz, G. (1983). Enxyme 30, 54-58.

Raul, F., Kedinger, M., Simon, P. M., Grenier, J. F. \& Haffen, K. (1981). Biology of the Neonate 39, 200-207.

Raul, F., Simon, P. M., Kedinger, M., Grenier, J. F. \& Haffen, K. (1978). Biology of the Neonate 33, $100-105$.

Reddy, B. S. \& Wostmann, B. S. (1966). Archives of Biochemistry and Biophysics 113, 609-616.

Rubino, A., Zimbalatti, F. \& Auricchio, S. (1964). Biochimica et Biophysica Acta 92, 305-31 1.

Simon, P. M., Kedinger, M., Raul, F., Grenier, J. F. \& Haffen, K. (1982). In Vitro 18, 339-346.

Tsuboi, K. K., Kwong, L. K., Ford, W. D. A., Colby, T. \& Sunshine, P. (198r). Gastroenterology $80,155^{\circ}-155^{6}$.

Williams, R. M. \& Beck, F. (1969). Fournal of Anatomy r05, 487-50 r.

Yeh, K.-Y. (1983). Fournal of Nutrition $113,1489-1495$.

Yeh, K.-Y. \& Moog, F. (1974). Science 182, 77-79.

Yeh, K.-Y. \& Moog, F. (1977). Fournal of Experimental Zoology 200, 337-348. 